\title{
IMPACT OF COVID-19 ON FINANCIAL MARKETS: CASE OF THE ITALIAN STOCK EXCHANGE
}

\author{
MAHFOUd DJEBBAR*, AdILA MERIMET ${ }^{* *}$
}

\begin{abstract}
The aim of this study is to shed light on the repercussions of Corona pandemic on financial markets. Using the Vector Autoregression, VAR, model, we estimate the relationship between the Italian Stock Exchange's Index, FTSEMib, and the number of cases and deaths by Covid-19 in Italy over the period February 24, 2020 to May 15, 2020. We find that both the number of infections and the number of deaths from Coronavirus negatively affect the stock market, and that the analysis of variance shows that the relative importance of daily infections by Covid-19 in explaining the fluctuations of the Italian Stock Exchange index has reached $17 \%$ in the medium and long terms, while the relative importance of daily deaths from Covid-19 in explaining the fluctuations of the Italian Stock Exchange index does not exceed $2 \%$ in the medium and long terms.
\end{abstract}

Keywords: Covid-19, financial markets, Italian stock exchange, VAR.

JEL Classification: $G 01, G 12, G 15, G 18$.

\section{INTRODUCTION}

Corona pandemic, known for short in the prevailing literature as Covid-19, appeared in Wuhan, a Chinese city, in late 2019, and then spread to Italy and Europe before it spread to the United States and the rest of the world within a few weeks. It greatly impacted all countries on the five continents, and influenced every country according to its economic structure and the precautionary measures it has taken, and pushed the World Health Organization, WHO, to declare it a world pandemic on 3/ 11/ 2020 (Zhang et al, 2020).

Coronavirus was not the first pandemic to hit humanity, but it was preceded by many pandemics such as the plague, or, as it is known, by the black death, which killed two-thirds of the population of medieval Europe; the Spanish flu, which caused the death of more than 50 million people in 1918 (Boissay and

\footnotetext{
* Setif 1 University, Algeria, Research Laboratory: LEMAC, e-mail: jebbar130299@yahoo.fr

*** Guelma University, Algeria, Research Laboratory: LSDRG, e-mail: merimet.adila@ univ-guelma.dz
} 
Rungcharoenkitkul, 2020), SARS in 2002, Ebola in 2013 and other pandemics. However, Covid-19 was distinguished from other pandemics in that it affected developing and developed countries alike, despite the latter's availability of enormous human and material capabilities; it is a global health crisis that has led to unexpected human and economic costs in a short period of time; it also came in a completely different international environment, where the world economy became more integrated and connected, and interest rates were very low or zero, or even on negative territory in some countries; it also affected both supply and demand for goods and services at the same time. Another feature is that this pandemic came in tandem with two trade wars, namely the trade war between China and the US, and the oil prices war between Russia and Saudi Arabia, which led to the collapse of its price to unprecedented levels.

This pandemic caused a severe shock to the whole world and took them by surprise, as the number of infected people in the world became in tens of millions and the number of deaths in millions, which prompted all countries to take multiple and strict measures to protect their populations from this devastating pandemic, and led to unprecedented repercussions on various economic, social and strategic levels. Educational institutions were closed, jobs were cut, borders closed to air, land, and sea navigation; restrictions were placed on the movement of individuals, and entire cities and regions were isolated in order to limit the transmission of the virus to them. In addition, shops and all non-essential activities were closed, and their peoples had to enter into strict measures, such as confinement and social distancing.

These measures caused severe damage to many economic and social sectors, and the most affected was the services sector, especially services related to domestic and international tourism, as the demand for these services decreased dramatically and suddenly, to the point of its absence in some cases as a result of canceling reservations. The transport industry of various kinds has also been strongly hit, among them airlines and cruise companies; as well as the hospitality industry, with millions of hotels, entertainment centers, restaurants, cafes, clubs and retail centers closed. High costs of international transactions in terms of exports and imports, that is, high costs of foreign trade, were also recorded due to the drop in global production of goods and services and the disruption of global supply chains, among other reasons. This has led to an unprecedented rise in unemployment rates in developed and developing countries with a service oriented economy, especially those that specifically depend on tourism. For example, the number of unemployed persons who applied for unemployment benefits reached 40.7 million workers in the USA during only 10 weeks, that is from mid-March to the end of May 2020 (CNN, 
5/29/2020). As a result, incomes fell, consumption dropped on a large scale and consequently consumer confidence was undermined.

In addition, impacted countries have taken many other measures to mitigate and contain the devastating effects of the pandemic, as they have canceled trade fairs, public gatherings, sports competitions and religious activities. They have also taken expansionary fiscal and monetary policies with the aim of providing liquidity and facilitating credit for banks and investors in affected economies, among other measures. Despite all of this, the human and economic costs were great by all standards, which called for international coordination and cooperation, whether in terms of intensifying efforts to find a vaccine for the pandemic or sharing necessary information and experiences to limit its wide impacts.

Returning to the topic of research, it can be said that financial markets, or FMs in short, collapsed with the expansion of the pandemic in various parts of the world, and their levels decreased in developed and emerging countries alike, for fear of slowing growth of the global economy, or even recording negative growth rates; occurrence of deep recession; increasing doubts about financial distress, and default of individuals who lost their jobs and companies that stopped their activities (AIMD, ASEAN, 2020). As a result, the stock and bond holders, i.e., individual investors and financial institutions, recorded heavy losses, especially after the central banks of most developed countries cut interest rates. Fear that the pandemic will lead to a deep economic and financial crisis, has led investors, after losing confidence in those markets, to resort toward safe havens and invest their money in other assets, such as treasury bonds, sovereign bonds, gold, and some commodities such as soybeans, West Texas Intermediate oil, WTI, some relatively stable currencies, and even cryptocurrencies, especially bitcoin, among other tools (Conlon and McGee, 2020; Corbert et al, 2020; Ji et al, 2020).

As a result of uncertainty and extreme volatility that has characterized the main FMs since the outbreak of Covid 19, contagion has spread to the rest of the global and emerging markets, and this led to an increase in risks and costs of lending, and to capital flight from developing markets towards safer havens in developed countries, which negatively affected the real economy. This also led to the collapse of stocks of affected companies such as airlines, financial institutions, energy companies, industrial companies among others. Accordingly, trading was halted in many global stock exchanges, that were panic-stricken; and investors lost confidence in dealing, as a result of the wide fluctuations in asset prices. For example, the trading floor of the New York Stock Exchange was closed to individual dealers for nearly 
two months, as its activity remained limited to electronic trading, then it was reopened on May 29, 2020 (CRS, Apr 17, 2020).

The rest of the article is organized as follows. The second section briefly deals with previous studies on the topic. The third analyses the financial markets' response to information related to Coronavirus, focusing on the New York Stock Exchange, since it is the locomotive of global financial markets. The fourth deals with the empirical study where the relationship between the Italian Stock Exchange Index and the number of cases and deaths from Covid-19 in Italy, was estimated. The fifth analyses the findings and the sixth concludes.

\section{RELATED LITERATURE}

Many studies focuse on the economic and social impacts of Corona pandemic, especially on human and economic costs, centering mainly on the hospitality industry, transport, tourism, foreign trade, unemployment, and so on (Boissay and Rungcharoenkitkul, 2020; Niestadt, 2020; Kochhar, 2020; Tagliapietra, 2020; Maliszewska and Matoo, 2020). While another part of literature is concerned with the impact of that pandemic on financial markets and increasing stock price volatility and their response to its development (Ramelli and Wagner, 2020; Sansa, 2020; Yan et al, 2020; Baker et al, 2020; Ashraf, 2020; Zhang et al, 2020; Al-Awadhi et al, 2020; Çitak et al, 2020). The third part pays attention to safe havens in times of crisis such as bitcoin, some stable currencies such as the Swiss franc and the Japanese yen, gold, oil and a limited number of other commodities, such as soy (Gil-Alana and Aikins Abakah, 2020; Corbet et al, 2020; Conlon and McGee, 2020; Ji et al, 2020).

\section{FINANCIAL MARKETS' RESPONSE TO COVID-19}

A follower of global, emerging, and even active developing financial markets, during the first semester of 2020, can easily note that those markets ignored the emergence of Corona pandemic at the beginning of the year 2020, and some of them achieved the highest levels ever, although the pandemic appeared in late 2019. But as soon as the pandemic spread in China and first death cases were recorded, those markets panicked and suddenly collapsed in a few days. However, after several months, they returned to relatively acceptable levels, ignoring once again that the pandemic continues to claim many lives, especially in the US, and inflicting more losses to the global economy (see Table 1 and Appendix 1). 
Figure 1: Evolution of the number of cases, WTC, and the number of deaths, WTD, in the world during the first half of 2020

(On a bi-monthly basis)

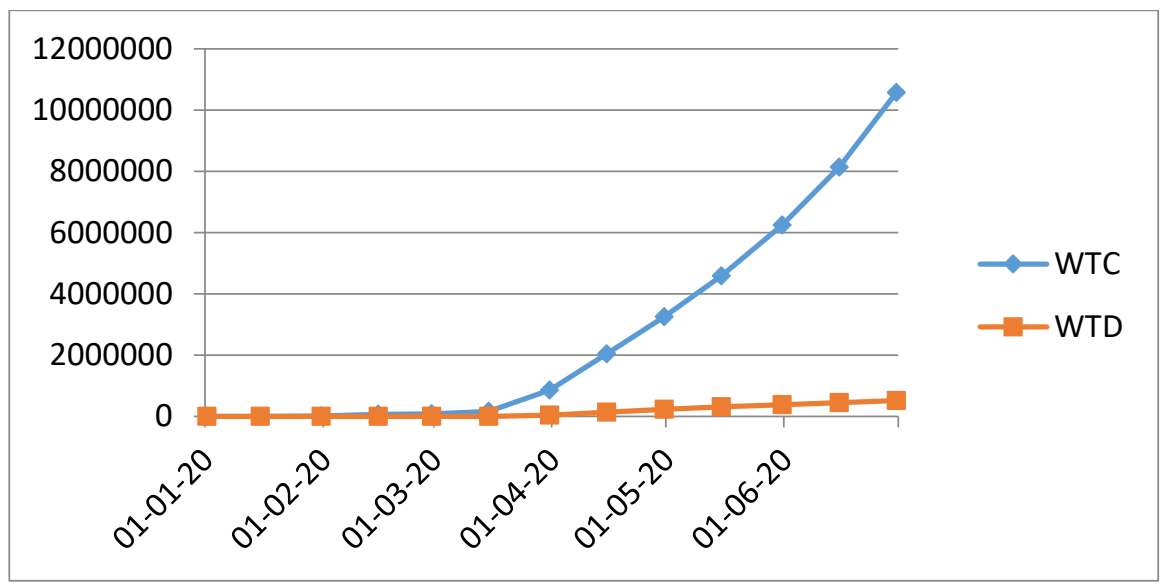

Source: Authors' calculations based on statistics available at: https://www.worldometers.info/coronavirus/

It is noticed from the previous figure, that the number of confirmed cases worldwide, WTC, was increasing in a geometric sequence, as it accelerated in the last weeks of this semester in a real fearful way. It reflects the great impact of this pandemic on all aspects of life in the world, including financial markets, which is the subject of our study, as they collapsed in a relatively short period of time and lasted at lower levels for weeks thenafter.

Accordingly, FMs collapsed, as previously mentioned, in response to "bad" news received, and mainly related to Covid-19, especially the number of deaths since mid-February 2020, as share prices of industrial companies and financial institutions, that decreased or even stopped their activities after the pandemic spreading, and consequently, experienced credit defaults for their bad loans. Thus, FMs panicked, price volatility and investment risks increased, resulting to a wide correction process. Experts of the World Bank, WB, believe that this pandemic has led to the following (W.B., March 25, 2020):

- Global FMs volatility and re-pricing of various assets;

- Lack of liquidity in the global FMs;

- Flight of capital from developing and emerging countries, and the appreciation of the US dollar against most currencies; 
- Lack of (and in some cases no) dealing in bonds, including the closing of their primary markets; and high borrowing costs;

- Stronger negative effects were reported on small and undeveloped FMs.

In the same context, Baker et al, 2020, believes that FMs responded in an unprecedented way, not only to Covid-19, but also to the strict measures that were taken by various countries to limit the spread of the pandemic on their soil, especially stopping many activities and services and restricting individuals' movement, in a service oriented economy. In addition to contagion effects, FMs negatively responded to the length of time the pandemic lasts, the number of victims, and the speed at which it spreads in the five continents; while they positively responded to policy responses, economic recovery programs, and rescue packages.

These programs have taken various forms, such as lowering interest rates, IRs, as happened in the US, where the Fed cut IRs to nearly zero on March 15, and lowered the required reserve ratio (reserve requirements), to zero for the first time in history. The US government also decided to acquire $\$ 700$ billion worth of available assets, and pump 2.3 trillion dollars into the US economy to overcome the devastating effects of the pandemic. For its part, the European Central Bank, ECB, announced the purchase of $\$ 820$ billion of bonds; and thenafter many countries followed suit in taking measures related to monetary and fiscal policies, aiming to calm FMs and providing liquidity to the economy. Moreover, countries also adopted a considerable number of programs to strengthen health and social sectors (CRS, Apr 17, 2020; CRS), Jun. 4, 2020).

Despite all this, stock markets lost about 6 trillion dollars in a single week, i.e. from 24-28 February 2020, and the S\&P 500 lost more than 5 trillion dollars of its value during the same week (Ozili, 2020). During the period from February 19 to March 20, 2020, Dow Jones lost 34.67\% of its value, British FT lost 31.35\%, German Dax lost 34.72\%, Italian FTSEMib 37.90\%, French CAC 33.52\% and Spanish Ibex 33.67\% (www.statista. com, 2020). This led to the trading suspension on many global stock exchanges during March 2020, due to sharp decline in asset prices. For example, on the morning of Monday, March 9, 2020, the S\&P 500 fell by $7 \%$ after 4 minutes of trading, and Dow Jones fell by 7.8\% and lost about 2013 points, which is the largest loss since the global financial crisis in 1987 (Black Monday, October 19, 1987), that triggered the Automatic Circuit Breaker ${ }^{1}$ for the

\footnotetext{
- ${ }^{1}$ - The automatic circuit breaker is a system that was developed by the Securities and Exchange
} Commission, SEC, after the collapse of 1987, with the aim to automatically halt trading in case of 
first time since the 2007-8 financial crisis, and trading was halted on Wall Street and major US stock exchanges for 15 minutes (CRS, Apr. 3, 2020; CRS, Apr. 17, 2020). Wall Street continued to decline losing 2,999 points on March 16, the biggest oneday loss in Dow Jones' history (Fernandes, 2020; AIMD, 2020).

In addition to trading suspension and opening for shorter trading days in FMs, and in order to limit wide fluctuations, many countries such as the UK, the US, France, Italy, Korea, Spain, Turkey and Indonesia have banned short selling deals ${ }^{2}$, which are usually characterized by intense speculation. Stock buybacks have also been prohibited in several countries (CRS, Apr 3, 2020; FSB, Apr. 15, 2020).

Among the price fluctuation signals that global FMs experience from time to time, is the number of deviations or jumps, which are the cases of daily highs and lows in the market index that are greater than $2.5 \%$ compared to the previous day's closing prices, as these jumps affect FMs and represent their levels of risk. While there occurred 1143 jumps in the US financial markets from January 2, 1900 to April 30,2020 , hence about 9.5 jumps per year; 18 jumps were recorded only in 22 trading days, i.e., from February 24 to March 24, 2020, which is the highest in one month ever. This means that the number of jumps during this pandemic is 20 times higher than the average number since 1900 (Baker et al, Apr 2020). If this indicates anything, then it indicates the high intensity of FM fluctuations during this period, in response to the evolution of the pandemic on the one hand, and to measures taken by countries, such as monetary policies, financial policies, etc., on the other.

In the same order of ideas, the Market Volatility Index, known for short as VIX, is also used as the expected volatility barometer for FMs. It is based on options prices, and has its roots in 1973. Accordingly, since this index was affected by Corona

prices collapse to an extent that harms market liquidity. According to the instructions of that commission, there are 3 thresholds or level, namely:

- The first level: a drop of 7\% of the S\&P 500, compared to the previous day's closing price, triggers trading suspension for 15 minutes. Trading is not stopped if the decline occurs after 3:25 p.m;

- The second level: a drop of $13 \%$ of the S\&P 500, compared to the previous day's closing price, triggers trading suspension for 15 minutes. Trading is not stopped if the decline occurs after 3:25 p.m;

- The third level: a drop of 20\% of the S\&P 500, compared to the previous day's closing price, leads to the trading suspension for the rest of the day (www.sec.gov).

2 - Short selling is a strategy that is utilized in financial markets, whereby the investor sells a security that does not actually own, but he borrows it from a broker or an asset management company and sells it at the market price. In this case, the seller is betting on a decline of the security's price in the short term. Therefore, as soon as its price drops, he buys it and delivers it to the broker or company before the deal's due date. Despite the possibility of making high profits, as a result of dealing in this form of speculation, these transactions are not without high risks and the possibility of making unlimited losses, when the investor's expectations are not met. Financial authorities require this seller to have a specific financial guarantee that he puts in a special account. 
pandemic it means higher price fluctuations of FMs, and consequently, high levels of risk. This is due mainly to the number of cases, deaths, and the number of affected countries. The high VIX reflects optimism among market participants, while low VIX reflects the possibility of a market correction (Fernandes et al, without date).

What attracts attention here is that, the most important and largest global FMs, achieved relatively high or record levels at the beginning of the year 2020, despite the emergence of the pandemic in China at the end of 2019, which means that they completely ignored that event at the beginning, as we have already indicated. So, the Dow Jones reached 29,551 points on 12/ 02/ 2020, the S\&P 500 reached 3386 points on 19/ 02/ 2020, the highest level in its history; Dax 13,789 points on 19/ 02/ 2020; the FT 7675 points on 04/ 02/ 2020; and the Japanese Nikkei 24041 points on 17/ 01/ 2020 (https://tradingeconomics.com). It should be noted here that, the American FMs, as the locomotive of global FMs, have witnessed a successive rise over the last 11 years, that ended in mid-March 2020, which is the longest upward period ever, and that ended with the fastest collapse in its history as well (CRS, Apr 3, 2020 ). That is why the last correction of these markets and other global FMs, which coincided with this pandemic, was devastating and caused heavy losses to investors in a few weeks, as previously indicated.

Figure 2: Evolution of the Dow Jones during the period: 03/ 02/ 2020 to 15/ 05/ 2020

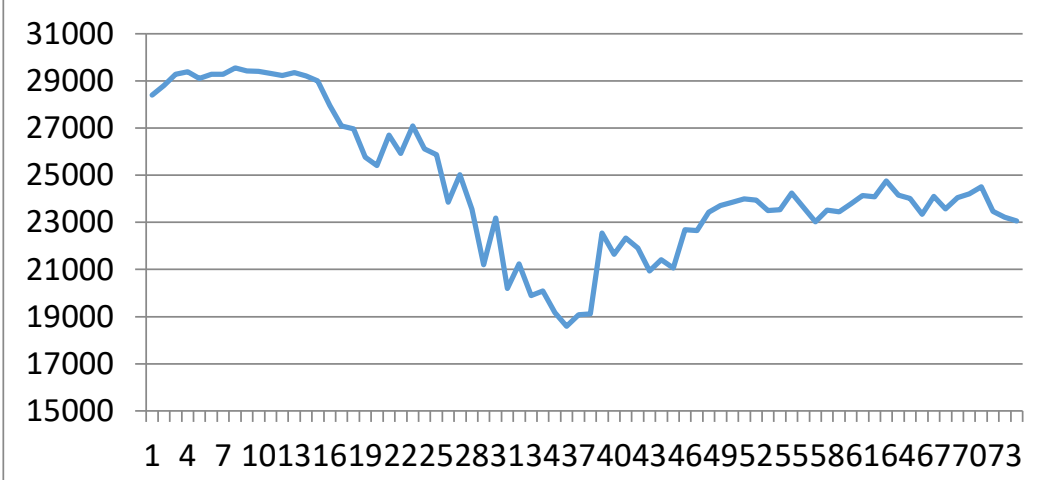

Source: Authors' calculations based on statistics available at: https://www.worldometers.info/coronavirus/

However, during the period in which the crisis intensified, Dow Jones rolled rapidly from February 12, 2020 to March 23, 2020, reaching its lowest level during the first half of this year 2020 . 
Figure 3: Evolution of the Dow Jones during

the period $12 / 02 / 2020$ to $23 / 03 / 2020$

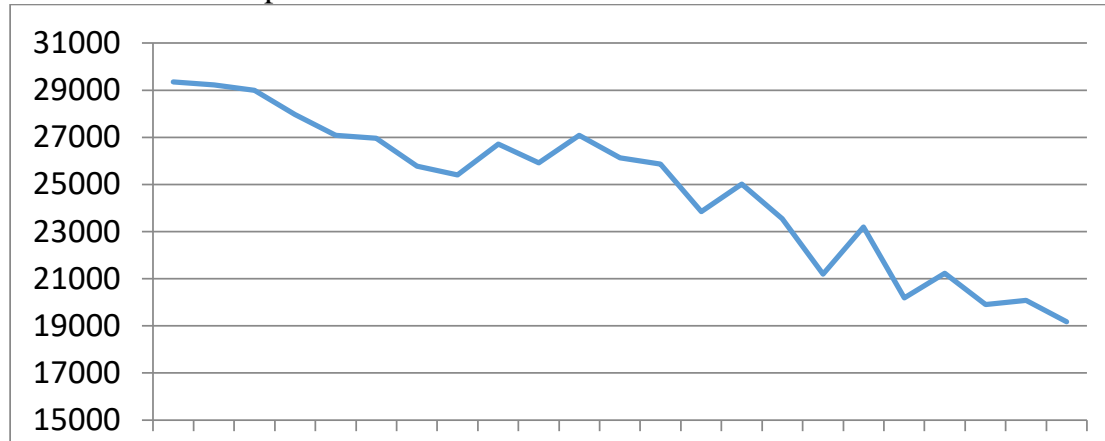

$122 \quad 3 \quad 4 \quad 5 \quad 6 \quad 7 \quad 8 \quad 91011121314151617181920212223$

Source: Authors' calculations based on statistics available at: https://www.worldometers.info/coronavirus/

Accordingly, and after recording these positive results before the spread of the pandemic, global FMs witnessed very low levels in a few days, and even collapsed completely once Covid-19 moved from China to Europe, and then to the US and the rest of the world. Fortunately, these markets are also back to acceptable levels after several weeks.

Table-1: Evolution of indexes for some global FMs during the first semester of 2020 Unit: point

\begin{tabular}{|c|c|c|c|c|c|c|c|c|c|}
\hline Index & country & date & Val 1 & data & Val 2 & Ch\% $1 *$ & date & Val 3 & Ch 2* \\
\hline DJ & US & $12 / 02$ & 29551 & $23 / 03$ & 18591 & -39.09 & $08 / 06$ & 27594 & +48.43 \\
\hline FT & GB & $04 / 02$ & 7675 & $23 / 03$ & 4930 & -35.77 & $05 / 06$ & 6484 & +31.52 \\
\hline Dax & Ger & $19 / 02$ & 13789 & $18 / 03$ & 8489 & -38.44 & $05 / 06$ & 12848 & +51.35 \\
\hline Mib & Italy & $19 / 02$ & 25305 & $12 / 03$ & 14930 & -41.00 & $08 / 06$ & 20231 & +35.51 \\
\hline CAC & France & $19 / 02$ & 6064 & $18 / 03$ & 3750 & -38.16 & $05 / 06$ & 5198 & +38.61 \\
\hline Ibex & Spain & $19 / 02$ & 10083 & $16 / 03$ & 6071 & -39.79 & $08 / 06$ & 7896 & +30.06 \\
\hline Shgh & China & $05 / 03$ & 3071 & $23 / 03$ & 2662 & -13.32 & $30 / 06$ & 2985 & +12.13 \\
\hline
\end{tabular}

Source: Authors' calculations based on statistics available at: https://tradingeconomics.com

(*) Change 1 represents the ratio between value 2 and value 1 ; while change 2 is the ratio between the value 3 and the value 2 .

From the previous table, it is noted that the sharpest and widest decline was recorded in the Italian market $-41 \%$ in about 3 weeks, as this market experienced a shock after the quick outbreak of the pandemic in Italy. On the contrary, the Chinese financial market was the most stable, compared to the rest of global FMs and recorded a decline of $13.32 \%$ during the crisis and recovered about $12.13 \%$ by the 
end of the first half of 2020. On the whole, most FMs have not achieved new record levels after this crisis, but came somewhat close to the levels at which they were at the beginning of the year, then ignoring the actual skyrocketing number of cases and deaths due to Covid-19 all over the world, and that there were no signs on the horizon to find a vaccine for it.

Here it must also be noted that the collapse was not limited to stocks alone, but rather sovereign financial instruments suffered the same crisis, as yields on US Treasury bonds fell to historical levels on March 6 and then on March 9, 2020. What deepens the problem is the shift of investors from stocks to those safer instruments, and to sovereign bonds in general, driven by expectations of lower corporate returns, and consequently lower equity returns (CRS, Apr 17, 2020).

\section{EMPIRICAL STUDY}

During this part of the study, the relationship between the Italian Stock Exchange Index and the number of confirmed cases and the number of deaths from Covid-19 in Italy, will be estimated, by following the methodological steps and using the statistical and mathematical tools and methods appropriate to our study.

\subsection{The Model}

The model used in this study is the P-order Vector Autoregressive, VAR, model, that takes the following form (Ben Habib, w.d; Bechichi, 2016):

$$
Y_{\mathrm{t}}=\delta+\phi_{1} \mathrm{Y}_{\mathrm{t}-1}+\phi_{2} \mathrm{Y}_{\mathrm{t}-2}+\cdots+\phi_{\mathrm{p}} \mathrm{Y}_{\mathrm{t}-\mathrm{p}}+\varepsilon_{\mathrm{t}}
$$

where:

$Y_{t}$ is the value of the variable in the current period;

$Y_{t-1}, Y_{t-2}, \ldots, Y_{t-p}$ are the values of the variable in previous periods;

$\varepsilon_{t}$ is the term error in the current period;

$\delta$ is the intercept

The VAR model, using the lagged term L, usually takes the form:

$$
Y_{t}=\delta+\phi_{1} L Y_{t-1}+\phi_{2} L^{2} Y_{t-2}+\cdots+\phi_{p} L^{p} Y_{t-p}+\varepsilon_{t}
$$

After simplifying and rearranging, we get:

$$
\phi(L) Y_{t}=\delta+\varepsilon_{t}
$$

where

$$
\phi(L)=\left(1-\phi_{1} L-\phi_{2} L^{2}-\cdots-\phi_{p} L^{p}\right)
$$




\subsection{Study variables}

The study variables are:

- the Milan Stock Exchange Index, referred to as "MIB", is the main index at Italiana Stock Exchange, the Italian national stock exchange, and measures the performance of 40 most liquid Italian stocks and largest capitalizations. Currently, it is known as the FTSE MIB, since the British FTSE Group has acquired $50 \%$ of its shares;

- the daily number of confirmed cases of Covid-19: "IC"; and

- the daily number of deaths from Coronavirus: "ID".

The time series for the study, i.e., MIB, IC and ID, variables are obtained from the following websites: https://www.worldometers.info/coronavirus/ https://tradingeconomics.com; https://www.statista.com, that are available in the form of moving figures. Figure 4 below depicts the evolution of these variables during the period Feb. 24, 2020 to May 15, 2020.

Figure 4: Evolution of the variables used in the study

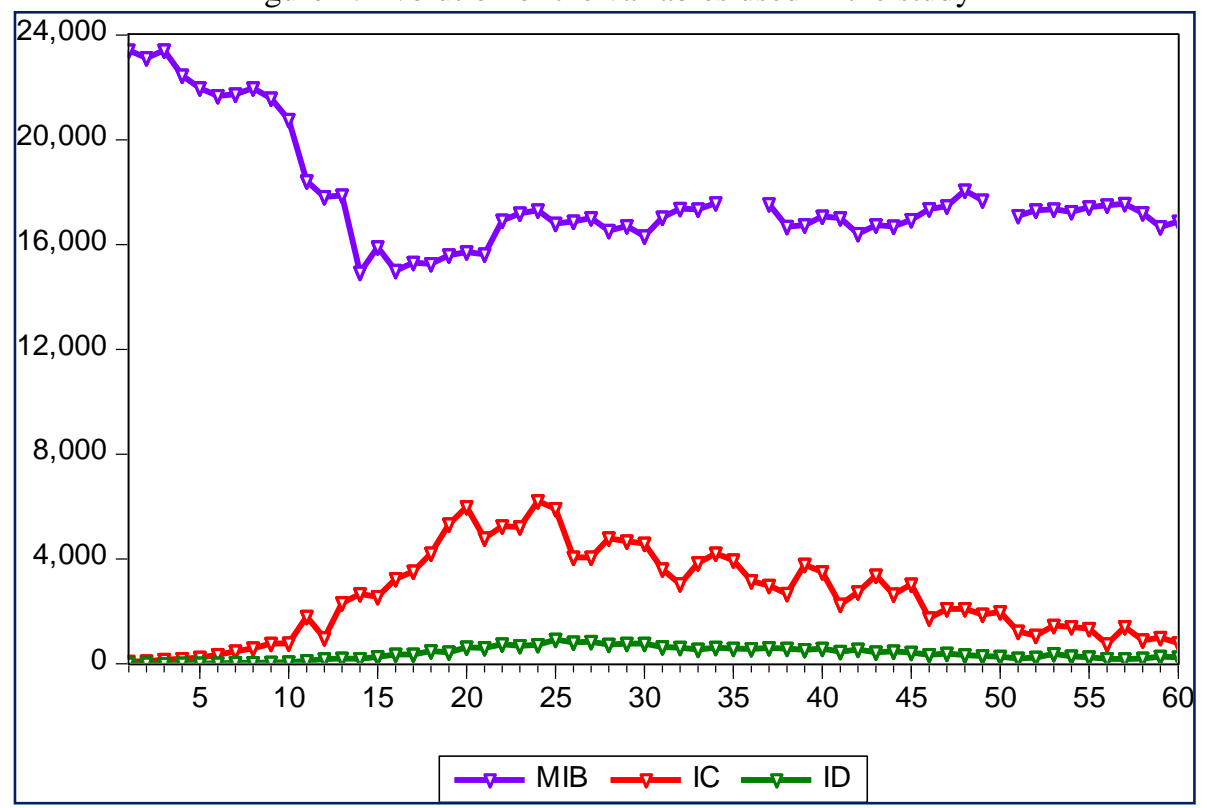

Source: Authors' calculations based on Eviews8 software output.

\subsection{Stationarity tests}

To ensure the stationarity of the time series of the variables used in our study, we utilize the Augmented Dickey-Fuller, ADF, to test for the null hypothesis, which means that the time series contain a unit root, i.e. nonstationary; and the alternative 
hypothesis, which means that they do not contain a unit root, and therefore, they are stationary. The following table shows these tests.

Table- 2: Augmented Dickie-Fuller, ADF, test for time-series stationarity

\begin{tabular}{lllll}
\hline Variables & $\begin{array}{l}\text { ADF Test Statistic } \\
\text { at Level }\end{array}$ & $\begin{array}{c}\text { ADF Test Statistic at } \\
1^{\text {st }} \text { Diffrence }\end{array}$ & $\begin{array}{l}5 \% \text { Critical } \\
\text { Value }\end{array}$ & Decision \\
\hline MIB & -1.986784 & -2.471033 & -3.513075 & non-stat \\
IC & -3.136165 & -1.689399 & -3.496960 & non-stat \\
ID & -0.938017 & -10.68203 & -3.489228 & stationar \\
\hline
\end{tabular}

Source: Authors' calculations based on Eviews8 software output.

Table 2, above, shows that, we reject the null hypothesis with respect to the variable ID, because the absolute value of ADF Test Statistic at the first difference is greater than the absolute value of the $5 \%$ critical value, i.e., it is stationary at the first difference and cointegrated of the order I(1). However, for the other variables, MIB and IC, the null hypothesis is accepted due to the existence of the unit root and, consequently, the nonstationarity of the time series for these two variables at the Level and at the first difference, because the absolute values of ADF Test Statistic are less than the absolute values of the $5 \%$ critical values. This, necessitates studying their stationarity at the second difference. Table 3 shows these tests.

Table- 3: Augmented Dickie-Fuller, ADF, Unit Root Test at Second Difference

\begin{tabular}{llll}
\hline Variables & $\begin{array}{l}\text { ADF Test Statistic } \\
\text { at } 2^{\text {nd }} \text { Difference }\end{array}$ & $\begin{array}{l}5 \% \text { Critical } \\
\text { Value }\end{array}$ & Decision \\
\hline MIB & -9.083365 & -3.513075 & stationary \\
IC & -9.674549 & -3.496960 & stationary \\
\hline
\end{tabular}

Source: Authors' calculations based on Eviews8 software output.

We note, here, that the absolute values of ADF Test Statistic at the second difference are greater than the absolute values of the $5 \%$ critical values, and accordingly, we reject the null hypothesis for the two variables MIB and IC, that is, they are stationary at the second difference and cointegrated of the order I(2).

To sum up, stationarity tests indicate that the variables are stable at their second difference, except for the number of deaths, ID, which is stationary at its first difference; and accordingly:

- cointegration cannot be tested, because variables do not have the same order of cointegration; and

- causality cannot be tested, because it places restrictions on parameters of the variables to be tested, and it also assumes the stationarity of all variables. 
This prevents the use of the vector error correction model, VECM, to study the relationship between the Italian Stock Exchange Index, MIB, and the number of cases and deaths from Covid-19 in Italy, and this calls for the use of the unrestricted VAR model that does not require the cointegration between time series.

Therefore, the relationship between Covid-19 and the Italian stock exchange index will be studied as a short-term phenomenon, since we are not looking for a long-term equilibrium relationship to the evolution of the economy (Boucha, 2012).

\subsection{Selection of the optimal lag order}

Before estimating the model, it is necessary to select the lag order $(\mathrm{Nd})$ of the VAR model defined for this series, as this is the most difficult stage in building timeseries models; and therefore the optimal lag length should be selected, depending on a set of criteria shown in the following table:

Table- 4: Tests to select the optimal lag order

VAR Lag Order Selection Criteria

Endogenous variables: DDMIB DDIC DID

Exogenous variables: $\mathrm{C}$

Date: 06/23/20 Time: 16:36

Sample: 160

Included observations: 39

\begin{tabular}{lllllll}
\hline \hline Lag & LogL & LR & FPE & AIC & SC & HQ \\
\hline \hline 0 & -878.8059 & NA & $8.74 \mathrm{e}+15$ & 45.22082 & 45.34878 & 45.26673 \\
1 & -853.7116 & 45.04113 & $3.84 \mathrm{e}+15$ & 44.39547 & $44.90733^{*}$ & 44.57912 \\
2 & -838.1307 & 25.56865 & $2.77 \mathrm{e}+15$ & 44.05798 & 44.95375 & 44.37938 \\
3 & -825.3494 & $19.00811^{*}$ & $2.33 \mathrm{e}+15^{*}$ & $43.86407 *$ & 45.14373 & $44.32320^{*}$ \\
4 & -820.3219 & 6.703329 & $2.99 \mathrm{e}+15$ & 44.06779 & 45.73135 & 44.66466 \\
\hline \hline
\end{tabular}

* indicates lag order selected by the criterion

Source: Authors' calculations based on Eviews8 software output.

From the precedent table, we notice that most criteria have chosen the third lag order as an optimum lag length, that we can use to estimate the VAR model.

\subsection{Estimation of the VAR model}

The VAR model is as follows:

VAR=F(DID, DDIC, DDMIB, C) 
Assuming that all variables are endogenous, meaning that they change within the model, i.e., their values can be predicted internally; and after selecting the lag order $(\mathrm{Nd}=3)$, we estimate the Vector Autoregression, VAR, model, using the results of the assessment and the Eviews8 software described in Appendix 2. The estimated relationship can be summarized as follows:

$$
\begin{aligned}
& \text { MIB = 8.487 - 0.91 DDMIB(-1) -0.44 DDMIB(-2) -0.037DDMIB(-3) -0.286DDIC(-1) -0.17DDIC(-2) } \\
& \text {-0.21DDIC(-3) +2.33DID(-1) +0.46DID(-2) -1.05DID(-3) } \\
& \mathrm{F}=5.194759 \quad \bar{R}^{2}=0.4794 \quad R^{2}=0.5937
\end{aligned}
$$

From the above estimated equation, we note that:

- from an economic point of view, we find that the Italian Stock Exchange Index has a negative relationship with the daily number of infections with Covid-19, during the three lagged terms. The Index also responds negatively to the daily number of deaths during the same lagged terms; and therefore, we can admit that the model is economically acceptable;

- $\quad$ with regard to the adjusted coefficient of determination, $\bar{R}^{2}$, which is estimated at 0.4794 , meaning that $47.94 \%$ of the change in the Italian Stock Exchange is explained by the lagged variables at three lagged terms;

- by testing the overall significance of the model, it is found that the calculated F-statistic is greater than the tabulated F-statistic (2.60), that is, there is at least one variable that is not equal to zero, and therefore, the model is statistically acceptable.

It is evident from the previous model, that there is a negative effect of medium strength of the daily number of cases of Coronavirus at three lagged periods, on the performance of the Italian Stock Exchange, i.e., a one unit change in IC leads to a decrease in MIB of 0.286 points at the first lagged period, and it decreases by 0.17 and 0.21 During the second and third lagged periods, respectively. It was also evident that there is a negative effect of medium strength of the daily number of deaths from Covid-19 at three lagged periods, on the performance of the Italian Stock Exchange, which appears at the third lagged period, i.e., a one unit change in ID leads to a decrease in MIB of 1.05 points. 


\subsection{Stability of the model}

In order to trust the VAR model results and their explanatory capacity of the relationships between variables, the stability of this model must be tested; since its instability makes the obtained results incorrect. The following figure summarizes the results of testing its stability.

Figure 5: VAR Model Stability Test

Inverse Roots of AR Characteristic Polynomial

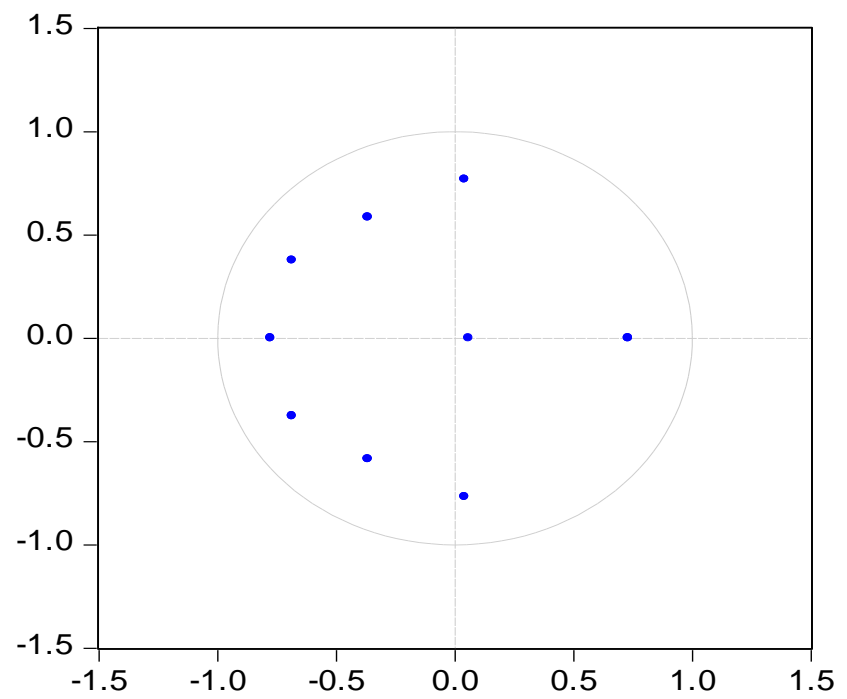

Source: Authors' calculations based on Eviews8 software output.

It is evident from the figure that, all the inverse roots of AR characteristic polynomial lie within the unit circle, and this means that the estimated VAR model is stable.

\subsection{Dynamic analysis of the model}

Perhaps the most important characteristic of VAR models is the possibility of studying the dynamic behavior of the relationships between variables, and this through the functions of response pulses and variance segmentation.

4.7.1. Analysis of response pulses functions. The results of the test of the functions of response pulses are as shown in the following figure. 
Figure 6: Response pulse functions

Response of DDMIB to DDIC

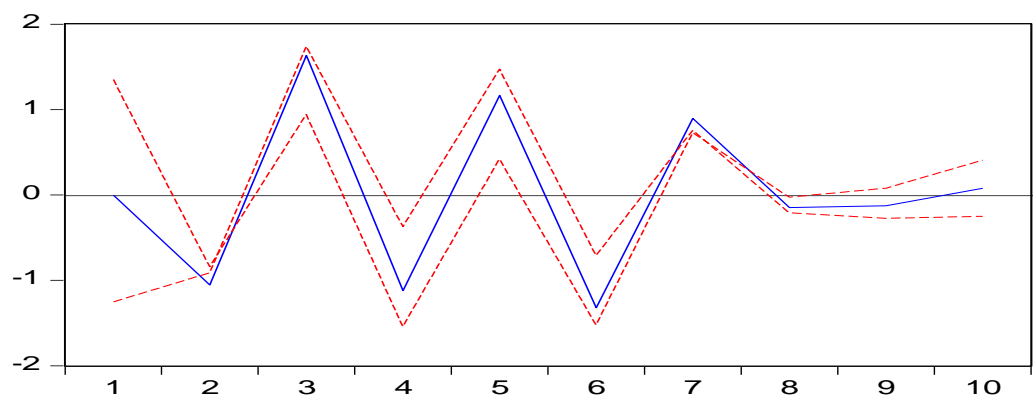

Response of DDMIB to DID

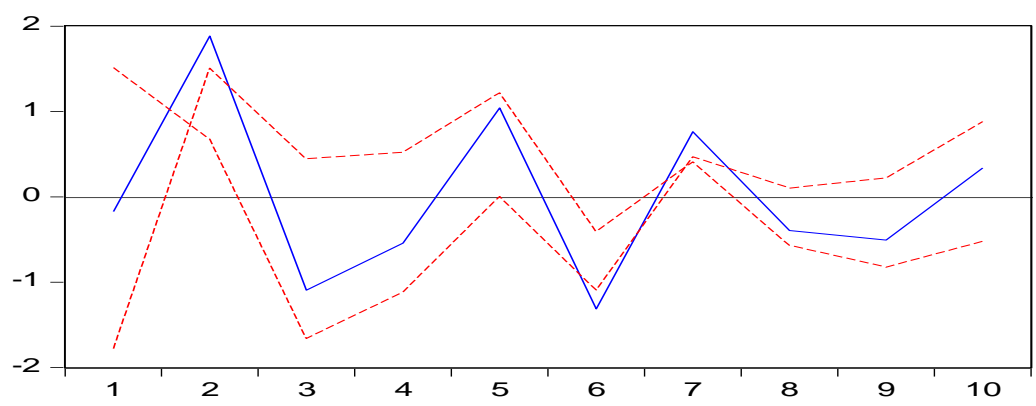

Source: Authors' calculations based on Eviews8 software output.

Through the above figure, we note that the occurrence of a positive structural shock to the number of daily infections with Covid-19, IC, amounting to $1 \%$, led to a zero response $(0 \%)$ to the Italian Stock Exchange index, MIB; it decreases and becomes negative by $1.1 \%$ in the second year of the shock. This response quickly turns into a positive one by $1.6 \%$ in the third year, then it becomes negative again in the fourth year, and remains at the same pace where it becomes positive and then negative in the following years and, so that the effect becomes almost non-existent starting from the eighth year of the shock.

Moreover, the occurrence of a positive structural shock amounting to $1 \%$ in the daily number of deaths from Covid-19, led to a negative and weak response of the Italian Stock Exchange index of $0.2 \%$. This response quickly turns into a positive one of $1.9 \%$ in the second year after the shock. Then the response becomes negative again in the third and fourth years, and fluctuations in the response remains between positive and negative during the rest of the period. 
4.7.2. Variance segmentation. An analysis of variance shows the relationship between variables and the effect of each of them on the other, by determining the amount of variance in the prediction for each variable, due to the prediction error in the same variable and the amount due to the prediction error in other variables. The following table shows the results of the variance segmentation.

Table 5: Results of the variance segmentation test for the Italian Stock Exchange index

\begin{tabular}{ccccc}
\hline \hline Period & S.E. & DDMIB & DDIC & DID \\
\hline \hline 1 & 765.6379 & 100.0000 & 0.000000 & 0.000000 \\
2 & 1059.559 & 95.78660 & 2.731984 & 1.481417 \\
3 & 1118.004 & 89.99536 & 8.408339 & 1.596303 \\
4 & 1138.062 & 87.62795 & 10.78989 & 1.582158 \\
5 & 1164.584 & 84.96121 & 13.09981 & 1.938983 \\
6 & 1189.259 & 81.80568 & 15.97333 & 2.220986 \\
7 & 1200.679 & 80.35079 & 17.23129 & 2.417914 \\
8 & 1201.261 & 80.31637 & 17.25463 & 2.428999 \\
9 & 1201.758 & 80.27321 & 17.26960 & 2.457188 \\
10 & 1202.437 & 80.21228 & 17.26270 & 2.525016 \\
\hline \hline
\end{tabular}

Source: Authors' calculations based on Eviews8 software output.

The above table illustrates the contribution of the study variables in explaining the change in the Italian Stock Exchange index, as we note that the circumstantial fluctuations that MIB index experienced are primarily caused by self-shocks of the variable itself during the first period of the shock. These shocks allow an explanation of $100 \%$ of changes in the Italian Stock Exchange Index. However, this percentage dropped to $95 \%$ in the second year and continues to decline at weak rates until it reached $81 \%$ in the sixth year; and remained close to $80 \%$ in the medium and long terms. In parallel with that, the relative importance of the daily number of infections with Covid-19, IC, in the interpretation of changes in the Italian Stock Exchange index increased from $2 \%$ in the second period to $8 \%$ in the third period of shock, and increased to $15 \%$ in the sixth period; and then remained constant during the last four periods, where it came close to $17 \%$. We also note the rise in the relative importance of the variable ID (the daily number of deaths from Covid-19) in explaining the fluctuations at the Italian Stock Exchange to $1.5 \%$ in early periods of the shock, and then remained close to $2.5 \%$ in the medium and long terms. 


\section{EMPIRICAL RESULTS}

This study attempts to estimate the relationship between the Italian Stock Exchange index and the daily number of infections and deaths from Covid-19 in Italy. It concludes:

- the existence of a statistically significant negative relationship between the daily number of infections with Covid-19 and the Italian Stock Exchange index;

- the existence of a statistically significant negative relationship between the daily number of deaths from Covid-19 and the Italian Stock Exchange index (appearing in the third lagged period);

- the analysis of random shocks shows that the occurrence of a positive shock in the daily number of infections with Covid-19 leads to a null response, and then negative one, to the Italian Stock Exchange index during the first and second periods respectively. This response turns into a positive one during the third period, and remains at the same frequency of fluctuation until the effect is almost non-existent starting from the eighth year of the shock. Almost the same observation can be made regarding the response of the Italian Stock Exchange index in the case of a positive structural shock in the daily number of deaths from Covid-19, then its responses fluctuate between positive and negative during the whole period;

- analysis of variance shows that the relative importance of the daily number of infections with Covid-19 in explaining the fluctuations of the Italian Stock Exchange index reached $17 \%$ in the medium and long terms, while the relative importance of the daily number of deaths with Covid-19 in explaining the fluctuations of the Italian Stock Exchange did not exceed 2\% in medium and long terms.

\section{CONCLUSION}

Corona pandemic began as a health and humanitarian crisis and turned into a devastating global economic and financial disaster, which prompted various countries of the world to take draconian measures to contain the virus and limit its effects. These measures, notably the suspension of many economic and social activities and the restriction of the movement of individuals over a period of several months, led to a considerable disruption in the global economy, a sharp decline in stock prices and wide fluctuation in global financial markets. Accordingly, by estimating the VAR model to determine the relationship between the Italian Stock 
Exchange index and each of the daily number of infections with Coronavirus and the daily number of deaths from the virus, we found that there is a negative impact of a medium strength of the daily number of infections with Covid-19 and the daily number of deaths from the virus lagged for three periods on the Italian Stock Exchange performance. This confirms the negative relationship between the performance of financial markets and this pandemic, i.e. the negative impact of Covid-19 on those markets. 


\section{APPENDICES}

Appendix 1: Some information on Coronavirus until 06/30/2020

\begin{tabular}{|l|r|r|c|c|}
\hline Country & $\begin{array}{c}\text { Number of } \\
\text { Cases }\end{array}$ & $\begin{array}{c}\text { Number of } \\
\text { deaths }\end{array}$ & $\begin{array}{c}\text { Date of } 1^{\text {st }} \\
\text { case }\end{array}$ & $\begin{array}{c}\text { Date of } 1^{\text {st }} \\
\text { death }\end{array}$ \\
\hline USA & 2729060 & 130313 & $22 / 01 / 2020$ & $29 / 02 / 2020$ \\
\hline GB & 283253 & 43730 & $31 / 01 / 2020$ & $05 / 03 / 2020$ \\
\hline Germany & 195832 & 9052 & $27 / 01 / 2020$ & $09 / 03 / 2020$ \\
\hline Italy & 240599 & 34767 & $31 / 01 / 2020$ & $21 / 02 / 2020$ \\
\hline France & 164801 & 29818 & $24 / 01 / 2020$ & $15 / 02 / 2020$ \\
\hline Spain & 296351 & 28355 & $01 / 02 / 2020$ & $03 / 03 / 2020$ \\
\hline China & 83531 & 4634 & $22 / 01 / 2020$ & $22 / 01 / 2020$ \\
\hline World & 10573550 & 517121 & $22 / 01 / 2020$ & $22 / 01 / 2020$ \\
\hline
\end{tabular}

Source: Authors' calculations based on statistics available at: https://www.worldometers.info/coronavirus/; and Ashraf, B.N., 2020.

Appendix 2: VAR model estimation results

Vector Autoregression Estimates

Date: 06/23/20 Time: 16:30

Sample (adjusted): 660

Included observations: 42 after adjustments

Standard errors in ( ) \& t-statistics in [ ]

\begin{tabular}{crrr}
\hline \hline & DDMIB & \multicolumn{1}{c}{ DDIC } & \multicolumn{1}{c}{ DID } \\
\hline \hline DDMIB(-1) & -0.913390 & 0.213984 & -0.008742 \\
& $(0.17914)$ & $(0.17989)$ & $(0.01375)$ \\
& {$[-5.09873]$} & {$[1.18953]$} & {$[-0.63571]$} \\
& & & \\
DDMIB(-2) & -0.444384 & 0.155683 & -0.009434 \\
& $(0.22901)$ & $(0.22997)$ & $(0.01758)$ \\
& {$[-1.94047]$} & {$[0.67698]$} & {$[-0.53663]$} \\
DDMIB(-3) & -0.037289 & 0.011719 & 0.017044 \\
& $(0.18552)$ & $(0.18629)$ & $(0.01424)$ \\
& {$[-0.20100]$} & {$[0.06291]$} & {$[1.19678]$} \\
& & & \\
DDIC(-1) & -0.286097 & -0.866094 & 0.020411 \\
& $(0.15986)$ & $(0.16053)$ & $(0.01227)$ \\
& {$[-1.78968]$} & {$[-5.39527]$} & {$[1.66326]$} \\
& & & \\
DDIC(-2) & -0.175251 & -0.576375 & 0.040299 \\
& $(0.18716)$ & $(0.18794)$ & $(0.01437)$ \\
& {$[-0.93637]$} & {$[-3.06674]$} & {$[2.80482]$}
\end{tabular}




\begin{tabular}{|c|c|c|c|}
\hline $\operatorname{DDIC}(-3)$ & $\begin{array}{r}-0.211442 \\
(0.16577) \\
{[-1.27552]}\end{array}$ & $\begin{array}{r}-0.333800 \\
(0.16646) \\
{[-2.00524]}\end{array}$ & $\begin{array}{r}0.036964 \\
(0.01273) \\
{[2.90472]}\end{array}$ \\
\hline DID $(-1)$ & $\begin{array}{c}2.334623 \\
(1.99413) \\
{[1.17075]}\end{array}$ & $\begin{array}{r}-4.044847 \\
(2.00248) \\
{[-2.01992]}\end{array}$ & $\begin{array}{r}-0.227891 \\
(0.15308) \\
{[-1.48867]}\end{array}$ \\
\hline DID $(-2)$ & $\begin{array}{c}0.463939 \\
(1.78216) \\
{[0.26032]}\end{array}$ & $\begin{array}{c}-1.935911 \\
(1.78962) \\
{[-1.08175]}\end{array}$ & $\begin{array}{r}0.466158 \\
(0.13681) \\
{[3.40732]}\end{array}$ \\
\hline DID(-3) & $\begin{array}{r}-1.053063 \\
(1.84711) \\
{[-0.57011]}\end{array}$ & $\begin{array}{r}1.408878 \\
(1.85485) \\
{[0.75957]}\end{array}$ & $\begin{array}{r}0.260167 \\
(0.14180) \\
{[1.83478]}\end{array}$ \\
\hline $\mathrm{C}$ & $\begin{array}{c}8.487103 \\
(120.818) \\
{[0.07025]}\end{array}$ & $\begin{array}{c}38.40190 \\
(121.323) \\
{[0.31652]}\end{array}$ & $\begin{array}{r}8.518976 \\
(9.27483) \\
{[0.91850]}\end{array}$ \\
\hline $\begin{array}{l}\text { R-squared } \\
\text { Adj. R-squared } \\
\text { Sum sq. resids } \\
\text { S.E. equation } \\
\text { F-statistic } \\
\text { Log likelihood } \\
\text { Akaike AIC } \\
\text { Schwarz SC } \\
\text { Mean dependent } \\
\text { S.D. dependent }\end{array}$ & $\begin{array}{r}0.593665 \\
0.479384 \\
18758443 \\
765.6379 \\
5.194759 \\
-332.7946 \\
16.32355 \\
16.73728 \\
10.69048 \\
1061.120\end{array}$ & $\begin{array}{r}0.590395 \\
0.475194 \\
18915788 \\
768.8422 \\
5.124901 \\
-332.9700 \\
16.33191 \\
16.74564 \\
28.88095 \\
1061.299\end{array}$ & $\begin{array}{r}0.538784 \\
0.409067 \\
110547.0 \\
58.77578 \\
4.153535 \\
-224.9815 \\
11.18959 \\
11.60332 \\
10.38095 \\
76.45912\end{array}$ \\
\hline $\begin{array}{l}\text { Determinant resid } \\
\text { Determinant resid } \\
\text { Log likelihood } \\
\text { Akaike informatior } \\
\text { Schwarz criterion }\end{array}$ & (dof adj.) & $\begin{array}{r}1.05 \mathrm{E}+15 \\
4.65 \mathrm{E}+14 \\
-888.0384 \\
43.71611 \\
44.95731\end{array}$ & \\
\hline
\end{tabular}

Source: Authors' calculations based on Eviews8 software output. 


\section{REFERENCES}

1. AIMD, ASEAN Secretariat, (2020), "Economic Impact of Covid-19 Outbreak on ASEAN", ASEAN Policy Brief, available at: https://asean.org/storage/2020/04/ASEAN-Policy-Brief-April2020_FINAL.pdf, consulted on 01/ 06/ 2020.

2. Al-Awadhi, A.M., Alsaifi, K, Al-Awadhi, A., Alhammadi, S., (2020), "Death and contagious infectious diseases: Impact of the COVID-19 virus on stock market returns", Journal of Behavioral and Experimental Finance 27, 2020.

3. Ashraf, B.N., (2020), "Stock markets' reaction to COVID-19: Cases or fatalities?", Research in International Business and Finance, 54, 2020.

4. Baker, S.R,. Bloom, N., Davis, S.J., Kost, K.J., Sammon, M.C., Viratyosin, T., (2020), "The Unprecedented Stock Market Impact of COVID-19”, NBER Working Paper 26945, available at: http://www.nber.org/papers/w26945, consulted on 03/ 05/ 2020.

5. Bechichi, W., (2016), "Role of Monetary Policy in Achieving Economic Growth in Light of the Current Economic Reforms", a PhD Thesis in Economic Sciences, Annaba University, Algeria.

6. Ben Habib, T., (nd), "Steps to apply VAR technique using Eviews", available at:

7. https://drive.google.com/file/d/0Bx4rXkaBqpRja0YxNHdOR3hDSDA/view; consulted on 27/ 08/ 2020.

8. Boissay, F., (2020), and Rungcharoenkitkul, P., "Macroeconomic effects of Covid-19: an early review", BIS Bulletin, $N^{\circ}$ 7, 17 April 2020; available at: www.bis.org; consulted on 06/ 07/ 2020.

9. Boucha, M., (2012), "An Attempt to Assess the Results of the Monetary Policy in Light of the Economic Reforms: the case of Algeria for the period 1993-1998", a Ph.D. Thesis in Economics, University of Algiers 3.

10. Çitak, F., Bağcı, B., Şahin, E.E., Hoş, S., (2020), "Review of stock markets' reaction to COVID19 news: fresh evidence from Quantile-on-Quantile regression approach"; available at: https://ssrn.com/abstract=3596931; consulted on 14/ 07/ 2020.

11. CNN, 29/5/2020.

12. Conlon, T., McGee, R., (2020), "Safe haven or risky hazard? Bitcoin during the Covid-19 bear market", Finance Research Letters, 35, 2020.

13. Corbet, S., Larkin, C., Lucey, B., (2020), "The Contagion effects of the COVOD-19 pandemic: Evidence from gold and cryptocurrencies", Finance Research Letters, 35, 2020.

14. Gil-Alana, L.A., Aikins Abakah, I.J., Romero Rojo, M.F., (2020), "Cryptocurrencies and stock market indices. Are they related?" Research in International Business and Finance, 51, 2020.

15. CRS, Congressional Research Service, USA, (2020), "Covid-19 and Stock Market Stress", available at: https://crsreport.congress.gov, consulted on 06/ 08/ 2020.

16. Fernandes, M., Marcelo, M.C., Marcel, S., (nd), "Modeling and predicting the CBOE market volatility Index", WP No. 548, available at: http://hdl.handle.net/10419/176031; consulted on 15/ $06 / 2020$.

17. FSB, (2020), "COVID-19 pandemic: Financial stability implications and policy measures taken", Apr. 15, 2020, available at: http://www.fsb.org; consulted on 25/ 07/ 2020.

18. Ji, Q., Zhang, D., Zhao, Y., (2020), "Searching for safe-haven assets during the COVID-19 pandemic", International Review of Financial Analysis, 71, 2020.

19. Maliszewska, M., Matoo, A., Mensbrugghe, D., (2020), "The Potential Impact of COVID-19 on GDP and trade: A Preliminary Assessment”, World Bank WP $\mathrm{N}^{\circ}$ 9211, available at: http://www.worldbank.org/prwp; consulted on 05/ 05/ 2020. 
20. Niestadt, M., (2020), “The European Parliament, Covid-19 and the Tourism Sector, At a Glance”, available at: http://www.europarl.europa.eu/RegData/etudes/ATAG/2020/649368; consulted on 09/ 05/ 2020.

21. Ozili, P., (2020), "Spillover of COVID-19: impact on the Global Economy", available at: www.researchgate.net/publication, consulted on 17/ 06/ 2020.

22. Ramelli, S., Wagner, A.F., (2020), "Feverish Stock Price Reactions to COVID-19”, Swiss Finance Institute Research Paper Series $\mathrm{N}^{\circ} 20-12$; available at: https://ssrn.com/abstract=3550274; consulted on $20 / 06 / 2020$.

23. Sansa, N.A, (2020), "The Impact of COVID - 19 on the Financial Markets: Evidence from China and USA", available at: https://ssrn.com/abstract=3562530; consulted on 19/ 07/ 2020.

24. Tagliapietra, S., (2020), "COVID-19 is causing the collapse of oil markets: when will they recover?" April 23, 2020, available at: https://www.bruegel.org/2020/04/covid-19, consulted on 07/ 07/ 2020.

25. World Bank, (2020), “COVID-19 Outbreak: Capital Markets Implications and Response”, March 25, 2020; available at: http://www. pubdocs.worldbank.org ; consulted on 09/ 06/ 2020.

26. Yan, H., Tu, A., Stuart, L., Zhang, Q., (2020), "Analysis of the Effect of COVID-19 on the Stock Market and Potential Investing Strategies", available at: https://ssrn.com/abstract=3563380, consulted on $26 / 08 / 2020$.

27. Zhang D., Hu, M., Ji, Q., (2020), "Financial markets under the global pandemic COVID-19", available at: https://doi.org/10.1016/j.frl.2020.101528; consulted on 27/ 08/ 2020.

\section{Websites}

- https://www.worldometers.info/coronavirus/

- https://www.tradingeconomics.com

- https://www.statista.com 